Case Report

\title{
Primary Hydatid Cyst of Umbilicus, Mimicking an Umbilical Hernia
}

\author{
Mohammadreza Tarahomi, ${ }^{1}$ Hamidreza Alizadeh Otaghvar, \\ Nazila hasanzadeh Ghavifekr, ${ }^{3}$ Daryanaz Shojaei, ${ }^{4}$ \\ Farhood Goravanchi, ${ }^{5}$ and Amir Molaei ${ }^{5,6}$ \\ ${ }^{1}$ Plastic Surgery Department, Shahid Beheshti University of Medical Sciences, Tehran, Iran \\ ${ }^{2}$ Iran University of Medical Sciences and Shahid Beheshti University of Medical Sciences, Tehran, Iran \\ ${ }^{3}$ Urmia University of Medical Sciences, West Azerbaijan, Iran \\ ${ }^{4}$ Iran University of Medical Sciences, Tehran, Iran \\ ${ }^{5}$ Shahid Beheshti University of Medical Sciences, Tehran, Iran \\ ${ }^{6}$ Semnan University of Medical Sciences, Semnan, Iran
}

Correspondence should be addressed to Hamidreza Alizadeh Otaghvar; drhralizade@yahoo.com

Received 7 December 2015; Accepted 27 March 2016

Academic Editor: Nisar A. Chowdri

Copyright ( 2016 Mohammadreza Tarahomi et al. This is an open access article distributed under the Creative Commons Attribution License, which permits unrestricted use, distribution, and reproduction in any medium, provided the original work is properly cited.

\begin{abstract}
Hydatid cyst caused by Echinococcus granulosus demonstrates an endemic infection in several countries such as Middle Eastern countries. Liver is the most frequently involved organ, followed by the lung. The case we present is solitary primary localization of cyst in abdominal wall which is extremely rare. A 57-year-old woman presented with an abdominal wall lesion in umbilical area that had been evolving for about 2 years with recent complaint of pain and discomfort. We detected a midline abdominal mass $12 * 13$ centimeters in diameter which was bulged out in umbilicus. Preoperative clinical diagnosis of incarcerated umbilical hernia was made due to its physical examination while surgical exploration disproved the primary diagnosis and we found cystic mass adherent to superficial fascia without any communication to peritoneal space. The cyst was excised completely without any injury or perforation of containing capsule. The diagnosis of hydatid cyst was confirmed by histopathological examination of specimen. The retrograde evaluation showed no involvement of other organs. The patient was followed for two years and no recurrence of hydatid disease has been observed. Hydatid cyst should be considered as a differential diagnosis of abdominal wall and umbilical lesions especially in endemic regions.
\end{abstract}

\section{Introduction}

Hydatid disease is a zoonotic parasitic cystic disease caused by the larval stages belonging to the genus Echinococcus [1]. Echinococcus granulosus is widespread through many regions of Asia including Middle Eastern countries. Cystic hydatid disease is endemic in most parts of Iran and is hyperendemic in some areas [2]. Hydatidosis is responsible for approximately $1 \%$ of admission to surgical wards in Iran [2]. Liver is the most frequently involved organ. Hydatid cysts are mainly located in liver or lungs (78\%). The rest of the sites include muscle, peritoneum, bone, spleen, pancreas, heart, kidney, and brain $[2,3]$. The solitary primary localization in abdominal wall is extremely rare, and its incidence is unknown $[3,4]$. In our patient, the hydatid cyst was located in the umbilicus without any other primary involvement, mimicking an umbilical hernia, which makes this a rare case.

\section{Case Presentation}

A 57-year-old woman presented to surgical clinic in Tehran, Iran, with an abdominal wall lesion in umbilical area which had been evolving for about 2 years (Figure 1). Her complaint was emergence of pain and discomfort to her progressing lesion since the last week. She had not any past medical history of hydatid disease, surgical procedures, or any 


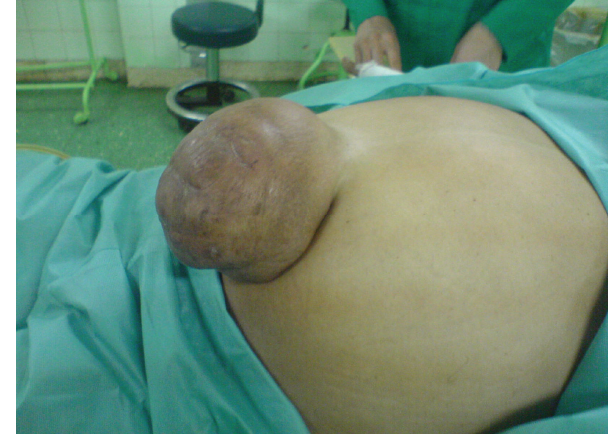

FIGURE 1: Umbilical cystic mass mimicking umbilical hernia.

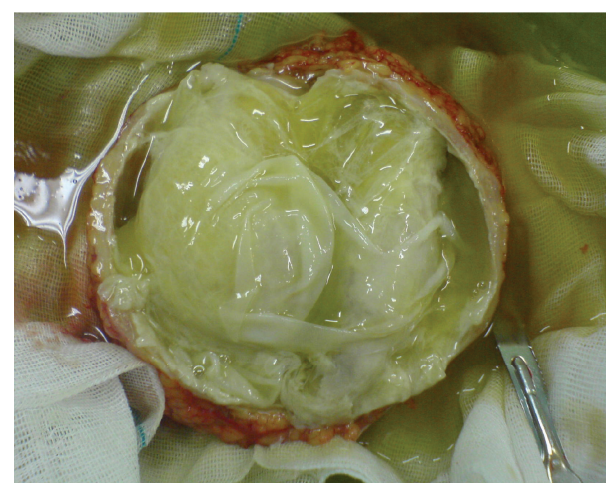

FIGURE 2: Macroscopic figure of mass.

infectious or parasitic disease. Her physical examination revealed a midline abdominal mass $12 * 13$ centimeters in diameter which was bulged out in umbilicus. The mass which was a painful swelling seemed to be cystic lesion with palpable solid components. Overlaying skin was intact with evidence of mild chronic irritation. Preoperative clinical diagnosis of incarcerated umbilical hernia was made due to its physical examination and recent symptoms such as pain. Therefore, she was scheduled for operative intervention. The preoperative examinations such as chest radiograph, complete blood count, blood biochemistry, and blood coagulation tests revealed no abnormalities. Complete blood count demonstrated white blood cell count of 9610 with 78 percent of neutrophils and no eosinophils. Surgical exploration disproved the primary diagnosis of umbilical hernia. The cystic mass was found to be adherent to superficial fascia without any communication to peritoneal space. It was not involved in peritoneum or abdominal organs. The cyst was excised completely and dissection was done without any injury or perforation of containing capsule and wound closure was done by primary repair. The macroscopic appearance of mass suggested a hydatid cyst and diagnosis was confirmed by histopathological examination of specimen (Figure 2). Postoperatively, the patient was investigated for other sites of concurrent involvements by hydatid disease. The retrograde evaluation by ultrasonography and chest radiograph showed no abnormalities in liver, lung, or other abdominal organs. No further medical treatment was prescribed. The patient was followed for one year and no recurrence of hydatid disease has been observed.

\section{Discussion}

Human hydatid disease is caused by Echinococcus granulosus and has a global distribution. Hydatid disease is known as an endemic parasitic disease in Iran and it is responsible for approximately $1 \%$ of admission to surgical wards [2]. Although the liver is the most commonly involved organ, the disease can be seen anywhere in the body [5].

It had been reported that primary muscle infection with E. granulosus accounts for $1 \%-4 \%$ of reported hydatid cases [6]. Low prevalence of this form of disease seems to be potentially due to the physical barriers to the hematogenous dissemination of cysts probably caused by hepatic sinusoids and pulmonary capillaries [7]. However, some cases of primary muscular involvement of various sites have been reported; reported cases include primary hydatid cyst located in biceps brachii [8], thoracic wall $[9,10]$, sartorius $[11,12]$, supraspinatus [13], gluteus [14], and soleus muscles [15].

Solitary abdominal wall hydatid cyst is a rare finding. We mentioned only a few cases reported to have primary abdominal wall lesions and most of them presented with right iliac or paraumbilical region [16-22]. Abhishek et al. reported a painless cystic swelling with intramuscular extension in right paraumbilical region [23, 24]. Burgazli et al. detected a subcutaneous palpable mass in the left quadrant paraumbilical region [3]. Erikci et al. also reported an intermuscular hard, painless, and immobile mass which was palpated in the right lower abdominal quadrant [21]. Besides, Popa et al. reported a 70-year-old Caucasian man who presented with a slow-growing painless parietal mass in the abdominal wall, in the right flank area, and the diagnosis of cystic mass was established at the clinical exam [22]. But none of them reported lesion exactly located in umbilicus.

In our case, presented region and acute symptoms brought to mind that misdiagnosis of umbilical hernia may be more probable. Due to the importance of intact resection in hydatid mass, any suspicious lesion during operation should be resected en bloc and prevented from rupture.

The patient surgery was based on our most possible diagnosis which was umbilical hernia, but in the operation room and under the surgery we found that the thing in that umbilical bulging is most likely a hydatid cyst. As a result of the pathology, our diagnosis was approved and the hydatid cyst was confirmed.

Surgery with total resection, if applicable, is the treatment of choice for primary hydatid cysts.

During resection, the wall should be kept intact and the resection should be done very carefully without causing any rupture. If not, dissemination of the disease and anaphylaxis may occur. Srivastava, though, suggests that hydatid cyst should be considered as a possible diagnosis of abdominal wall cystic lesions and open biopsy should be avoided. If resection of cyst in an intact form is not possible, removal of the content of the cyst should be considered. Endocystectomy, pericystectomy, marsupialization, capitonnage, simple drainage of the cyst, and resection of the infected organ 
are surgical methods used in practice. Then, the cavity of cyst should be irrigated with scolicidal agents [3, 4, 23-25]. In some studies, treatment with albendazole is suggested to be beneficial for preventing the postoperative recurrence of hydatid cyst disease of abdominal wall but with regard to the low prevalence of hydatid disease in abdominal wall, it was not yet studied $[3,23,24]$.

\section{Conclusion}

In endemic areas such as Iran, hydatid cyst should be considered as one of differential diagnosis in approaching the cystic lesions in any organ of the body even in abdominal wall or umbilicus. We suggested that, in the cases of primary hydatid disease in abdominal wall, complete resection is the treatment of choice.

\section{Competing Interests}

The authors declare that they have no competing interests.

\section{References}

[1] Y. F. Qi and W. P. Wu, "Progress on the epidemiology of echinococcosis," Zhongguo Ji Sheng Chong Xue Yu Ji Sheng Chong Bing Za Zhi, vol. 31, no. 2, pp. 143-148, 2013.

[2] S. M. Sharafi, M. Rostami-Nejad, M. Moazeni et al., "Echinococcus granulosus genotypes in Iran," Gastroenterology and Нераtology from Bed to Bench, vol. 7, no. 2, pp. 82-88, 2014.

[3] K. M. Burgazli, C. S. Ozdemir, E. B. Ozdemir, M. Mericliler, and Z. P. Polat, "Unusual localization of a primary hydatid cyst: a subcutaneous mass in the paraumbilical region," European Review for Medical and Pharmacological Sciences, vol. 17, no. 13, pp. 1766-1768, 2013.

[4] H. S. Özkan and B. Sahin, "Primary hydatid disease of subcutaneous tissue in the leg," Clinical and Experimental Dermatology, vol. 35, no. 8, pp. 915-916, 2010.

[5] E. O. Hamamci, H. Besim, and A. Korkmaz, "Unusual locations of hydatid disease and surgical approach," ANZ Journal of Surgery, vol. 74, no. 5, pp. 356-360, 2004.

[6] A. N. Freedman, "Muscular hydatid disease: report of a case and review of the literature," Canadian Journal of Surgery, vol. 17, no. 4, pp. 232-234, 1974.

[7] L. Cangiotti, P. Muiesan, A. Begni et al., "Unusual localizations of hydatid disease: a 18 year experience," Giornale di Chirurgia, vol. 15, no. 3, pp. 83-86, 1994.

[8] G. J. Duncan and S. M. T. Tooke, "Echinococcus infestation of the biceps brachii: a case report," Clinical Orthopaedics and Related Research, vol. 261, pp. 247-250, 1990.

[9] R. Alvarez-Sala, F. J. Gomez de Terreros, and P. Caballero, "Echinococcus cyst as a cause of chest wall tumor," Annals of Thoracic Surgery, vol. 43, no. 6, pp. 689-690, 1987.

[10] X. Chevalier, A. Rhamouni, S. Bretagne, J. Martigny, and B. Larget-Piet, "Hydatid cyst of the subcutaneous tissue without other involvement: MR imaging features," American Journal of Roentgenology, vol. 163, no. 3, pp. 645-646, 1994.

[11] M. R. Rask and G. J. Lattig, "Primary intramuscular hydatidosis of the sartorius. Report of a case," The Journal of Bone \& Joint Surgery-American Volume, vol. 52, no. 3, pp. 582-584, 1970.
[12] F. Duygulu, S. Karaoğlu, N. Erdoğan, and O. Yildiz, "Primary hydatid cyst of the thigh: a case report of an unusual localization," Turkish Journal of Pediatrics, vol. 48, no. 3, pp. 256-259, 2006.

[13] H. Tatari, Ö. Baran, T. Sanlidağ et al., "Primary intramuscular hydatidosis of supraspinatus muscle," Archives of Orthopaedic and Trauma Surgery, vol. 121, no. 1-2, pp. 93-94, 2001.

[14] A. Combalia and S. Sastre-Solsona, "Hydatid cyst of gluteus muscle. Two cases. Review of the literature," Joint Bone Spine, vol. 72, no. 5, pp. 430-432, 2005.

[15] H. Frayha, E. Togrul, A. Kalaci, Y. Sarpel, I. S. Koltay, and S. Øzbarlas, "What's your diagnosis?" Annals of Saudi Medicine, vol. 24, no. 4, pp. 288-309, 2004.

[16] P. Srivastava, A. N. Gangopadhyay, V. D. Upadhyaya, S. P. Sharma, and R. Jaiman, "An unusual presentation of hydatid cyst in anterior abdominal wall," Kathmandu University Medical Journal, vol. 6, no. 24, pp. 511-513, 2008.

[17] M. U. Amin, R. Mahmood, S. Manzoor, and S. Ahmad, "Hydatid cysts in abdominal wall and ovary in a case of diffuse abdominal hydatidosis: imaging and pathological correlation," Journal of Radiology Case Reports, vol. 3, no. 5, pp. 25-31, 2009.

[18] K. N. Ozoilo, D. Iya, A. T. Kidmas, O. Uwumarogie, and S. Hassan, "Anterior abdominal wall hydatid cyst; an unusual presentation," Nigerian Journal of Medicine, vol. 16, no. 2, pp. 181-182, 2007.

[19] A. Ousadden, H. Elbouhaddouti, K. Hassani Ibnmajdoub, K. Mazaz, and K. AitTaleb, "A solitary primary subcutaneous hydatid cyst in the abdominal wall of a 70-year-old woman: a case report," Journal of Medical Case Reports, vol. 5, article 270, 2011.

[20] N. M. Rao, V. Shanthi, B. A. Ramakrishna et al., "Anterior abdominal wall hydatid:a rare case report," Journal of Bioscience and Technology, vol. 2, no. 4, pp. 349-352, 2011.

[21] V. Erikci, M. Hoşgör, and N. Aksoy, "Primary abdominal wall hydatid cyst: a case report," Turkish Journal of Pediatrics, vol. 56, no. 2, pp. 183-185, 2014.

[22] C. Popa, S. Ionescu, C. M. Cretu et al., "A primary hydatid cyst in the abdominal wall-case report," Chirurgia, vol. 107, no. 5, pp. 655-658, 2012.

[23] V. Abhishek, V. S. Patil, U. Mohan, and B. S. Shivswamy, "Abdominal wall hydatid cyst: case report and review of literature," Case Reports in Surgery, vol. 2012, Article ID 583294, 6 pages, 2012.

[24] M. Ş. Ekşi, Y. Bayri, A. Saraçoğlu, S. Uyar Bozkurt, and D. Konya, "Primary subcutaneous hydatid cyst over thoracic spine: a case report and review of the literature," Türkiye Parazitoloji Dergisi, vol. 38, no. 4, pp. 264-269, 2014.

[25] P. Moro and P. M. Schantz, "Echinococcosis: a review," International Journal of Infectious Diseases, vol. 13, no. 2, pp. 125-133, 2009. 


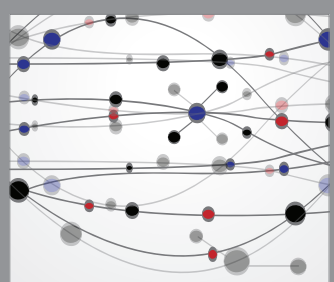

The Scientific World Journal
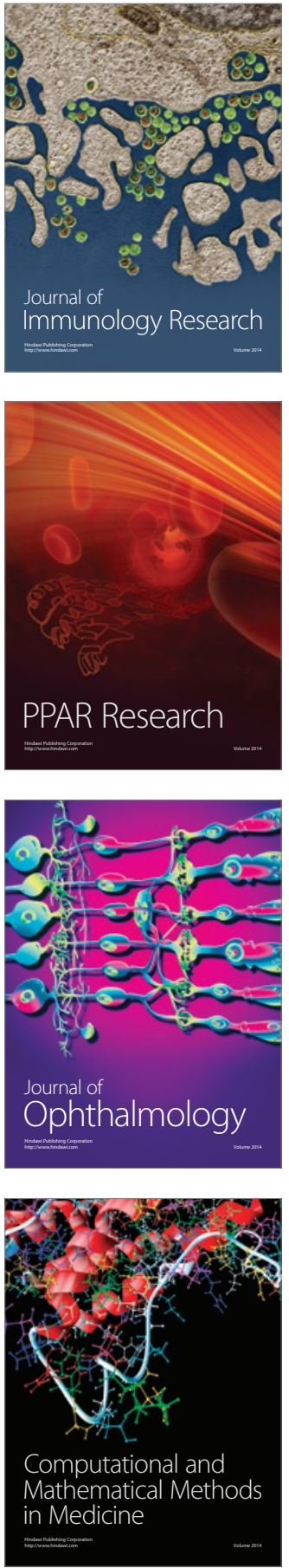

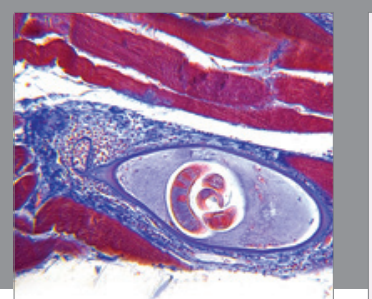

Gastroenterology Research and Practice

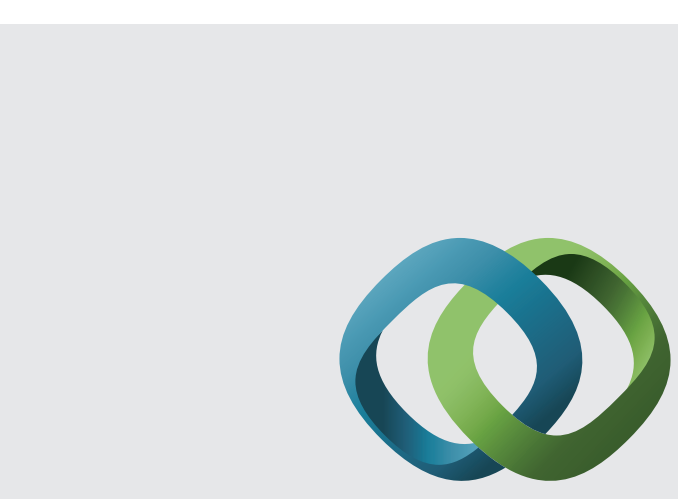

\section{Hindawi}

Submit your manuscripts at

http://www.hindawi.com
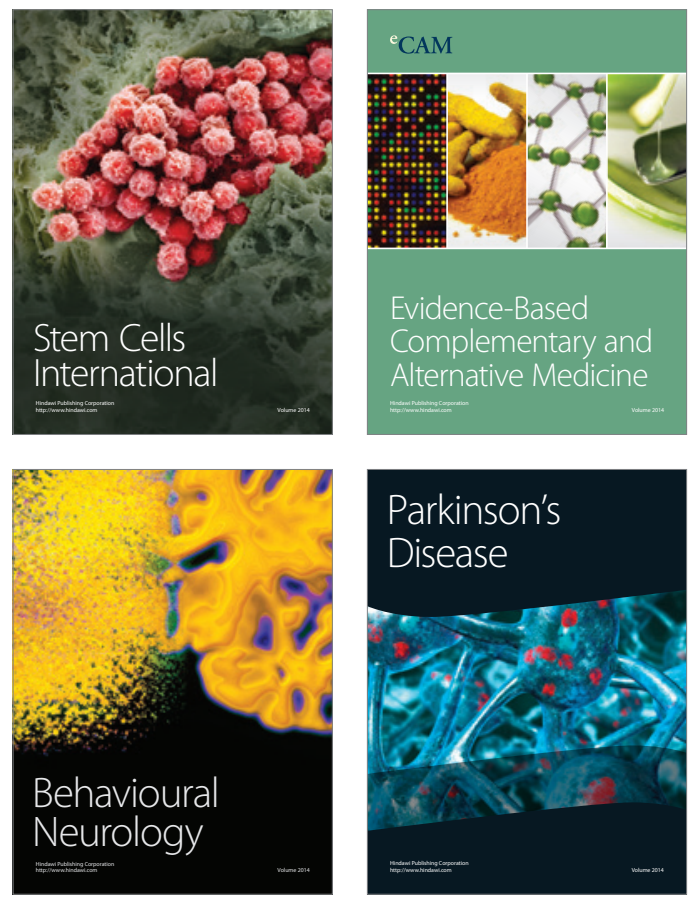
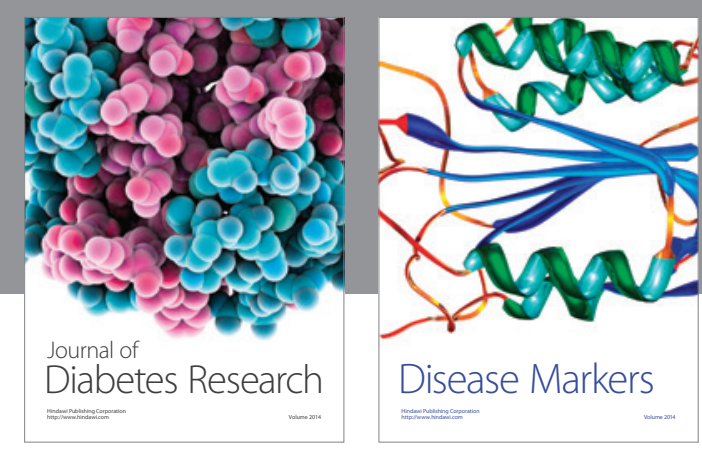

Disease Markers
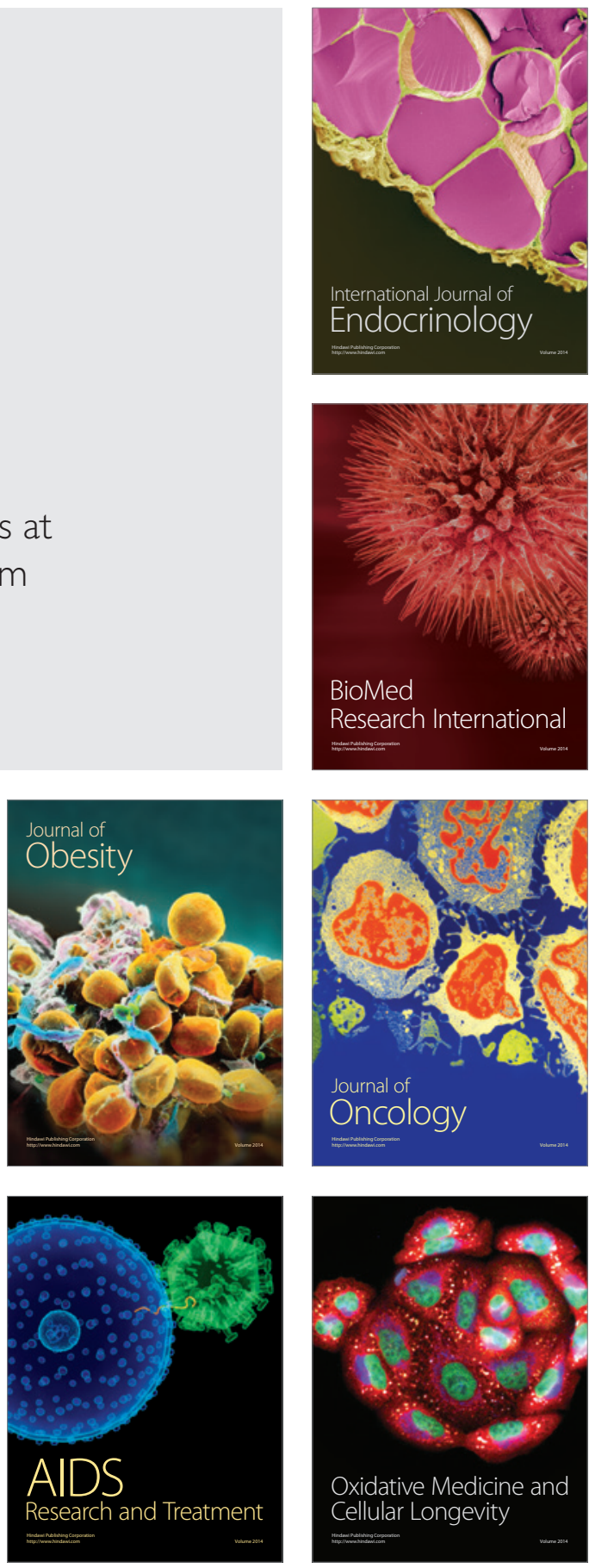